\title{
Potential drug-drug interactions in Alzheimer patients with behavioral symptoms
}

\author{
This article was published in the following Dove Press journal: \\ Clinical Interventions in Aging \\ 8 September 2015 \\ Number of times this article has been viewed
}

\author{
Giuseppe Pasqualetti \\ Sara Tognini \\ Valeria Calsolaro \\ Antonio Polini \\ Fabio Monzani \\ Geriatrics Unit, Department of \\ Clinical and Experimental Medicine, \\ University of Pisa, Pisa, Italy
}

\begin{abstract}
The use of multi drug regimens among the elderly population has increased tremendously over the last decade although the benefits of medications are always accompanied by potential harm, even when prescribed at recommended doses. The elderly populations are particularly at an increased risk of adverse drug reactions considering comorbidity, poly-therapy, physiological changes affecting the pharmacokinetics and pharmacodynamics of many drugs and, in some cases, poor compliance due to cognitive impairment and/or depression. In this setting, drug-drug interaction may represent a serious and even life-threatening clinical condition. Moreover, the inability to distinguish drug-induced symptoms from a definitive medical diagnosis often results in addition of yet another drug to treat the symptoms, which in turn increases drug-drug interactions. Cognitive enhancers, including acetylcholinesterase inhibitors and memantine, are the most widely prescribed agents for Alzheimer's disease (AD) patients. Behavioral and psychological symptoms of dementia, including psychotic symptoms and behavioral disorders, represent noncognitive disturbances frequently observed in AD patients. Antipsychotic drugs are at high risk of adverse events, even at modest doses, and may interfere with the progression of cognitive impairment and interact with several drugs including antiarrhythmics and acetylcholinesterase inhibitors. Other medications often used in AD patients are represented by anxiolytic, like benzodiazepine, or antidepressant agents. These agents also might interfere with other concomitant drugs through both pharmacokinetic and pharmacodynamic mechanisms. In this review we focus on the most frequent drug-drug interactions, potentially harmful, in $\mathrm{AD}$ patients with behavioral symptoms considering both physiological and pathological changes in AD patients, and potential pharmacodynamic/pharmacokinetic drug interaction mechanisms.
\end{abstract}

Keywords: AChEIs, Alzheimer, antipsychotic, drug-drug interaction

\section{Introduction}

A potential drug interaction is defined as an event in which two drugs known to interact were concurrently prescribed, regardless of whether adverse events occurred. ${ }^{1}$ Drug interactions may have potentially life-threatening consequences, especially in frail elderly subjects. ${ }^{2}$ Indeed, the elderly are particularly at an increased risk of adverse drug reactions (ADRs) considering comorbidity and the consequent poly-therapy as well as the age related changes of pharmacokinetics and pharmacodynamics of many drugs and, in some cases, the poor compliance due to cognitive impairment or behavior alteration. ${ }^{3,4}$ The use of multi drug regimens among the elderly population has increased tremendously over the last decade although the benefits of medications are always accompanied by potential harm (eg, adverse reaction due to drug-drug interaction), even when prescribed at recommended doses. ${ }^{2,3}$ An ADR is not always easy to recognize, especially in the elderly, in whom many clinical conditions coexist. Indeed, an ADR may be much more easily ascribed to "frailty" itself, an already existing
Correspondence: Fabio Monzani Geriatrics Unit, Department of Clinical and Experimental Medicine, University of Pisa, Via Savi 10, 56I 26 Pisa, Italy

Tel +39050997363

Fax +39050997352

Email fabio.monzani@med.unipi.it 
diagnosis or the onset of a new clinical problem rather than to a pharmacological adverse effect. For example, falls, delirium, drowsiness, lethargy, light-headedness, apathy, urinary incontinence, chronic constipation, and dyspepsia are frequently accepted as a primary diagnosis rather than a potential ADR. ${ }^{5}$ The inability to distinguish drug-induced symptoms from a definitive medical diagnosis often results in the addition of another drug to treat the symptoms increasing the risk of drug-drug interactions. ${ }^{5}$

Alzheimer's disease (AD) is the most common neurodegenerative disorder with a huge prevalence in the elderly population. This clinical condition is characterized by a slow progressive impairment of cognitive function. ${ }^{6}$ Psychiatric and behavioral symptoms are common in patients with AD and contribute substantially to the morbidity of the illness. ${ }^{7-9}$ Delusions or hallucinations appear in 30\%-50\% of AD patients and, as many as $70 \%$ of them exhibit agitated or aggressive behaviour. ${ }^{8}$ Considering the late onset of the syndrome, AD patients are often co-affected by other agerelated diseases such as systemic hypertension, heart disease, dyslipidemia, diabetes, arthritis, renal failure, endocrine alteration, neoplasm etc, and, consequently, receive several drugs. ${ }^{10,11}$ For a variety of reasons (eg, increased sensitivity to certain adverse effects, potential difficulty with adhering to a regimen, reduced ability to recognize and report adverse events) the risk of ADR may be less favorable in AD patients as compared to those without dementia. ${ }^{12,13}$

Generally, Alzheimer patients with mild-to-severe disease are treated by cognitive enhancers like acetylcholinesterase inhibitors (AChEIs) and memantine with the intent to decrease the rate of disease progression. ${ }^{14}$ Moreover, AD patients with behavioral symptoms need specific treatments such as psychotherapy and, when symptoms are not controlled, pharmacotherapy. As recommended by several authors, non-pharmacological interventions (eg, psychosocial/psychological counseling, interpersonal management, and environmental management) should be the first strategy and, when ineffective, it should be combined with specific drug classes for the shortest time possible. In particular, the most represented medications are first- and second-generation antipsychotic drugs. ${ }^{13,15-19}$ These medications present a high risk of adverse events, even at modest doses, and may favor the progression of cognitive impairment. ${ }^{20-22}$ Moreover, antipsychotics may interact with several drugs including antiarrhythmics and AChEIs. ${ }^{23,24}$ Long-term studies of efficacy and safety of antipsychotics in elderly patients have been limited in number, and some evidences suggest that antipsychotic drugs could be related with cardiovascular events (strokes and heart arrhythmia). ${ }^{25-30}$ In this review we focus on the most frequent drug-drug interactions, potentially harmful, in $\mathrm{AD}$ patients with behavioral symptoms. The potential pharmacodynamic/pharmacokinetic drug interaction mechanisms are also analyzed.

\section{Alzheimer patient-associated alterations affecting drug pharmacokinetics and pharmacodynamics}

Pharmacokinetics is the study of drug absorption, distribution, metabolism, and excretion. Drug pharmacokinetics is affected by several conditions related to the patients, such as genetic determinants and age related alterations. ${ }^{1}$ Considering the late onset of $\mathrm{AD}$, the major pharmacokinetic alteration of drugs, observed in Alzheimer patients, is similar to those described in the elderly population. The most important age-related processes, observed also in healthy old people, are related to muscle structure, liver and kidney function. ${ }^{31,32}$ In elderly patients, muscle mass and total body water are reduced $^{33}$ affecting pharmacokinetics of hydrophilic drugs with a smaller volume of distribution. Conversely, body fat increases from $20 \%$ to $40 \%$ with age, ${ }^{34,35}$ resulting in a larger volume of distribution of lipophilic drugs. The distribution of drugs into the central nervous system (CNS) tissue might be affected in the elderly considering that the blood-brain barrier becomes more porous in the elderly, resulting in drug availability to the CNS being increased. ${ }^{36}$ Moreover, in the elderly, an age-related decrease in the apparent liver blood flow has been reported. ${ }^{37,38}$ As a consequence, both total drug clearance and free drug clearance can decrease. However, the most significant organ changes in the elderly occur in the aging kidneys where a glomerulus loss is accompanied by a decrease in renal plasma flow. ${ }^{39}$

Pharmacodynamics is the study of the time course and intensity of drugs' pharmacologic effects. Pharmacodynamic interactions involve changes in a drug action on a receptor or a biologically active site. ${ }^{1}$ At pharmacodynamics level, although the biologic mechanisms in many cases are not well explained, elderly patients are particularly vulnerable to adverse effects related to CNS drugs, such as antipsychotics, including delirium, extrapyramidal symptoms, arrhythmias, and postural hypotension. ${ }^{40}$ Moreover, several age-related diseases increase the sensitivity to drug effects and lower the susceptibility threshold for drug-related adverse effects, independently of their mechanisms. For example, ageing is associated with increased sensitivity to the CNS effects of 
benzodiazepines: ${ }^{41,42}$ sedation is induced by diazepam at lower doses and lower plasma concentrations in elderly subjects. ${ }^{43,44}$ Ageing is also associated with increased sensitivity to the effects of nitrazepam, flurazepam, and loprazolam, ${ }^{45,46}$ but the exact mechanisms responsible for the increased sensitivity to benzodiazepines are unknown. Moreover, the elderly present a response to postural changes different from young subjects; indeed, cardiac output is maintained by increasing heart rate in the young, while in elderly subjects it is maintained by an increased stroke volume. ${ }^{41}$ These age related changes make the elderly more susceptible to the effects of drugs affecting cardiac rhythm or vasculature, as well as vagomimetic or antihypertensive drugs, resulting in an increased risk of hypotension episodes. ${ }^{41}$

However, if the pharmacokinetic changes in Alzheimer patients generally resemble those observed in the elderly population and several predisposing factors for ADR and drug-drug interactions are present among the normal elderly population, the pharmacodynamics of some CNS drugs may differ between normal elderly and Alzheimer patients. Indeed, AD selectively damages brain regions and neurotransmission pathways and is characterized by the presence of amyloid beta plaques and neurofibrillary tangles. ${ }^{47}$ Recent radiologic studies have shown that neuronal death is limited in normal aging, while in AD there is considerable neuronal loss. ${ }^{47,48}$ The latter is a constant feature and eventually the direct cause of dementia. Interestingly, the distribution of the pathological features of $\mathrm{AD}$ seems to follow a region-specific pattern: the amyloid plaques are more prevalent in the neocortex and the neuronal/synaptic loss is more represented in the hippocampus, posterior cingulate, and corpus callosum areas of the brain closely involved with memory formation and higher cortical activities. ${ }^{49-52}$ These pathological anatomical alterations underline a more complex modification in neurotransmission resulting in a reduction of the cholinergic transmission. The cholinergic system plays a fundamental role not only in the cognitive processes of dementia, but also in the behavioral symptoms associated with AD. Alterations in the cholinergic system can cause symptoms such as apathy, affective disorders, psychomotor impairment, agitation, and psychosis. ${ }^{53,54}$ Although the impaired neurotransmission in AD patients represents the major pharmacological target (especially cholinergic system) for disease treatment, it might also represent a point of weakness for AD patients, especially for those with behavioral symptoms, increasing CNS drug activity or sensitivity and thus favoring ADR and/or negative pharmacodynamic drug-drug interaction.

\section{Pharmacokinetic drug interaction}

Cognitive enhancers, including AChEIs and memantine, are the most widely prescribed agents for AD patients. The US Food and Drug Administration (FDA) has approved galantamine and rivastigmine for mild-to-moderate dementia, memantine for moderate-to-severe dementia, and donepezil for mild-to-severe dementia. ${ }^{55,56}$ Although these drugs did not present frequent pharmacokinetic drug interactions, in some cases they may occur. In the following section, we describe the major drug-drug interactions of $\mathrm{AD}$ pharmacological treatments. By definition, pharmacokinetic interactions involve alterations in the plasma concentration of a drug by a second agent that affects absorption, distribution, metabolism, and elimination phases. ${ }^{1}$

\section{AChEls}

As pharmacological class, AChEIs have relatively few pharmacokinetic interactions. However, considering that donepezil and galantamine are metabolized in the liver through CYP2D6 and CYP3A4, their hepatic metabolism may be affected by specific substrates, inhibitors, or enhancers of the same enzymes. ${ }^{57}$ Several drugs, reported in Table 1, may potentially interact with donepezil and galantamine at this level with different mechanisms: 1) by direct enzyme inhibition (eg, ketoconazole strongly inhibits CYP3A4 by non-competitive mechanism) and 2) competing for the catalytic site of the enzyme CYP3A4 (eg, benzodiazepines are metabolized by CYP3A4 cytochrome thus reducing the rate of transformation of the concurrent drugs eliminated by the same enzyme such as donepezil). ${ }^{58}$ Tiseo et al documented that in healthy humans the concurrent administration of ketoconazole and donepezil produces no change in ketoconazole plasma concentrations, but a statistically significant change in donepezil plasma concentrations. ${ }^{59}$ However, given that donepezil may be metabolized by two cytochromes (CYP3A4 and CYP2D6), the competitive inhibition with other CYP2D6 or CYP3A4 drug substrates, such as antidepressant or benzodiazepine, may not be clinically relevant. Interestingly, the oral coadministration of once-daily donepezil $5 \mathrm{mg}$ for 15 days and once-daily oral sertraline $(50 \mathrm{mg}$ for 5 days increased to $100 \mathrm{mg}$ for 10 days) did not result in any clinically significant pharmacokinetic interactions, and no unexpected ADRs were observed in healthy humans. ${ }^{60}$ Instead, the coadministration of galantamine with ketoconazole (CYP3A4 strong inhibitor) or paroxetine (CYP2D6 strong inhibitor) leads to a $30 \%$ and $40 \%$ increase, respectively, in galantamine exposure, compared to galantamine alone. ${ }^{61}$ The exposure to galantamine in patients with moderate and 
Table I List of important drugs that are substrates or inhibitors of cytochromes CYP2D6 and CYP3A4

\begin{tabular}{|c|c|c|c|c|c|}
\hline \multirow[t]{2}{*}{ Substance name } & \multicolumn{2}{|l|}{ CYP2D6 } & \multirow[t]{2}{*}{ Substance name } & \multicolumn{2}{|l|}{ CYP3A4 } \\
\hline & Substrates & Inhibitors & & Substrates & Inhibitors \\
\hline Amiodarone & & + & Albuterol & + & \\
\hline Aripiprazole & + & + & Alprazolam & + & \\
\hline Bupropion & + & + & Amiodarone & + & + \\
\hline Cimetidine & + & + & Aripiprazole & + & \\
\hline Citalopram & + & & Atorvastatin & + & + \\
\hline Donepezil & & + & Betamethasone & + & \\
\hline Duloxetine & + & & Buspirone & + & \\
\hline Fluoxetine & + & + & Carbamazepine & + & \\
\hline Galantamine & + & & Chlordiazepoxide & + & \\
\hline Haloperidol & + & + & Citalopram & + & \\
\hline Levomepromazine & + & + & Cortisol & + & \\
\hline Melperone & & + & Diazepam & + & \\
\hline Metoclopramide & & + & Diltiazem & + & + \\
\hline Moclobemide & & + & Donepezil & \pm & \\
\hline Norfluoxetine & + & + & Enalapril & + & \\
\hline Paroxetine & & + & Erythromycin & + & + \\
\hline Pergolide & & + & Escitalopram & + & \\
\hline Perphenazine & & + & Estrogens & + & \\
\hline Propafenone & & + & Etoricoxib & + & \\
\hline Propranolol & + & + & Finasteride & + & \\
\hline Sertraline & + & & Fluconazole & & + \\
\hline Thioridazine & + & & Fluvoxamine & \pm & + \\
\hline Trazodone & + & + & Galantamine & + & \\
\hline Tricyclic antidepressants & + & & Grapefruit juice* & + & \\
\hline Venlafaxine & + & & Haloperidol & + & + \\
\hline Fluphenazine & + & & Isosorbide & + & \\
\hline \multirow[t]{15}{*}{ Risperidone } & + & & Itraconazole & + & + \\
\hline & & & Itraconazole & + & + \\
\hline & & & Ketoconazole & + & + \\
\hline & & & Lansoprazole & + & \\
\hline & & & Mirtazapine & + & \pm \\
\hline & & & Nefazodone & + & + \\
\hline & & & Nifedipine & + & + \\
\hline & & & Quetiapine & + & \\
\hline & & & Raloxifene & + & + \\
\hline & & & Sertraline & \pm & + \\
\hline & & & Simvastatin & + & + \\
\hline & & & Trazodone & + & \pm \\
\hline & & & Triazolam & + & \\
\hline & & & Tricyclic antidepressants & + & + \\
\hline & & & Zolpidem & + & \\
\hline
\end{tabular}

Note: Data from Hiemke, ${ }^{68}$ Bressler, ${ }^{96}$ Ingelman-Sundberg, ${ }^{97}$ Zhou et al. ${ }^{98} \pm$, Weak inhibitory or inducing effect; +, significant inhibitory or inducing effect.

severe renal impairment is significantly higher than in healthy subjects, and is further approximately $30 \%$ higher in patients with moderate hepatic impairment. ${ }^{61,62}$ Therefore, attention should be paid when galantamine is coadministered with other drugs in patients with renal or hepatic impairment.

The competitive drug-drug interaction for the CYP may become clinically significant also in the elderly where an agerelated reduced hepatic and renal clearance (see "AChEIs" section) has been observed. It is noteworthy that rivastigmine, another AChEI, is least likely among the cognitive enhancers to have pharmacokinetic interactions with other medications since it does not undergo hepatic metabolism. Grossberg et al reported that rivastigmine did not lead to increased adverse events when administered concomitantly with 22 different classes of medications, including antidiabetic, cardiovascular, gastrointestinal, and nonsteroidal 
anti-inflammatory drugs in Alzheimer patients enrolled in a prospective study. ${ }^{63}$

\section{Memantine}

Memantine is a weak base with a pKa of 10.27 and it is predominantly excreted unchanged by the kidneys. ${ }^{64}$ Urine $\mathrm{pH}$ has been shown to be a major determining factor for the excretion of alkaline drugs like memantine, reducing the excreted amount. ${ }^{65}$ In this setting, Freudenthaler et al demonstrated a considerable effect of urine $\mathrm{pH}$ of healthy volunteers on memantine excretion. ${ }^{66}$ Since the renal excretion of memantine may have a relevant impact on the pharmacokinetic profile, changing of dietary habits that may alter urine $\mathrm{pH}$ should be avoided during treatment with such agent. Marked changes of urine $\mathrm{pH}$ might lead to tissue memantine overexposure resulting in toxic effects, especially in the elderly, where a reduced renal function has been described. Moreover, increased plasma levels of memantine may arise if coadministered with agents using the same renal cationic transport system as amantadine, such as cimetidine, ranitidine, procainamide, quinidine, quinine, and nicotine. ${ }^{67}$ Serum hydrochlorothiazide levels may be reduced by coadministration with memantine, and patients treated with warfarin should be monitored for possible increases in international normalized ratio or prothrombin time. ${ }^{67}$

\section{Miscellaneous}

Other pharmacokinetic drug-drug interactions that may occur in Alzheimer patients are related to psychiatric drugs such as benzodiazepine, antidepressant, and antipsychotic agents that are largely used in such patients, especially for behavioral alterations. In this setting, the major part of pharmacokinetic drug-drug interactions is related to hepatic metabolism (Table 1). For example, hepatic CYP enzymes of the phase 1 metabolism are most susceptible, regarding the pharmacokinetic interactions of antipsychotic drugs. ${ }^{24}$ Among the multiple isoenzymes in the liver, CYP1A2, CYP2C19, CYP2D6, and CYP3A4 are practically relevant for the degradation of antipsychotic drugs. ${ }^{68}$ Coadministration of an antipsychotic drug with paroxetine, a potent inhibitor of CYP2D6, may lead to elevated plasma concentrations of the antipsychotic drug, and thus enhance concentrationdependent side effects such as extrapyramidal symptoms. ${ }^{57}$ Other pharmacokinetic drug-drug interactions that may occur in patients are represented by hepatic enzyme induction, thus resulting in reduced tissue exposure and/or drug failure. In the clinical setting, the most important inducers of CYP1A2 are polycyclic aromatic hydrocarbons that are present in
Table 2 Principal CYP3A4 inducer drugs

\begin{tabular}{l}
\hline Drug name \\
\hline Carbamazepine \\
Efavirenz \\
Dexamethasone \\
Lovastatin \\
Oxybutynin \\
Rifabutin \\
Rifampicin \\
Phenobarbital \\
Phenytoin \\
Primidone
\end{tabular}

Note: Data from Spina et al, ${ }^{57}$ Hiemke, ${ }^{68}$ Ingelman-Sundberg,,${ }^{97}$ Zhou et al. ${ }^{98}$

cigarette smoke. For CYP3A4, carbamazepine is the most important inducer. ${ }^{69,70}$ As example, a susceptible substrate of CYP3A4 is represented by quetiapine; it was described that quetiapine plasma concentration decreases by approximately $90 \%$ when coadministered with carbamazepine. ${ }^{69,70}$ Inducer enzyme drugs that may affect the pharmacokinetics of other drugs are listed in Table 2.

\section{Pharmacodynamic drug interaction}

Pharmacodynamic drug-drug interactions may result from an antagonistic or synergistic mechanism. Several CNS drugs may interact directly at the receptor level or indirectly affecting one or more neurotransmission system. In particular, the risk to develop an ADR related to a negative drug-drug interaction is increased in the elderly due to CNS ageing alterations and may be more relevant in Alzheimer patients (see the previous section). The cholinergic theory of $\mathrm{AD}^{71}$ has led to development of the cholinesterase inhibitors. When used appropriately, these medications may slow the decline in cognition and functional impairment associated with AD. However, based on their opposing mechanisms of action, concomitant use of cholinesterase inhibitors and anticholinergics may result in pharmacological antagonism (Figure 1). ${ }^{72}$

\section{Cholinergic antagonism}

The anticholinergic effect is a feature of several drugs such as antipsychotics, antidepressants, antihistamines, bronchodilators, drugs for urinary incontinence etc. There is evidence that the use of these classes of drugs, even in non-Alzheimer elderly individuals, is considered potentially inappropriate ${ }^{73}$ and the use of anticholinergics by those with dementia is especially troubling because these individuals are more prone to develop medication-induced cognitive impairment. ${ }^{73}$ It is noteworthy to mention that tertiary anticholinergics such as atropine have been successfully used as an antidote for 


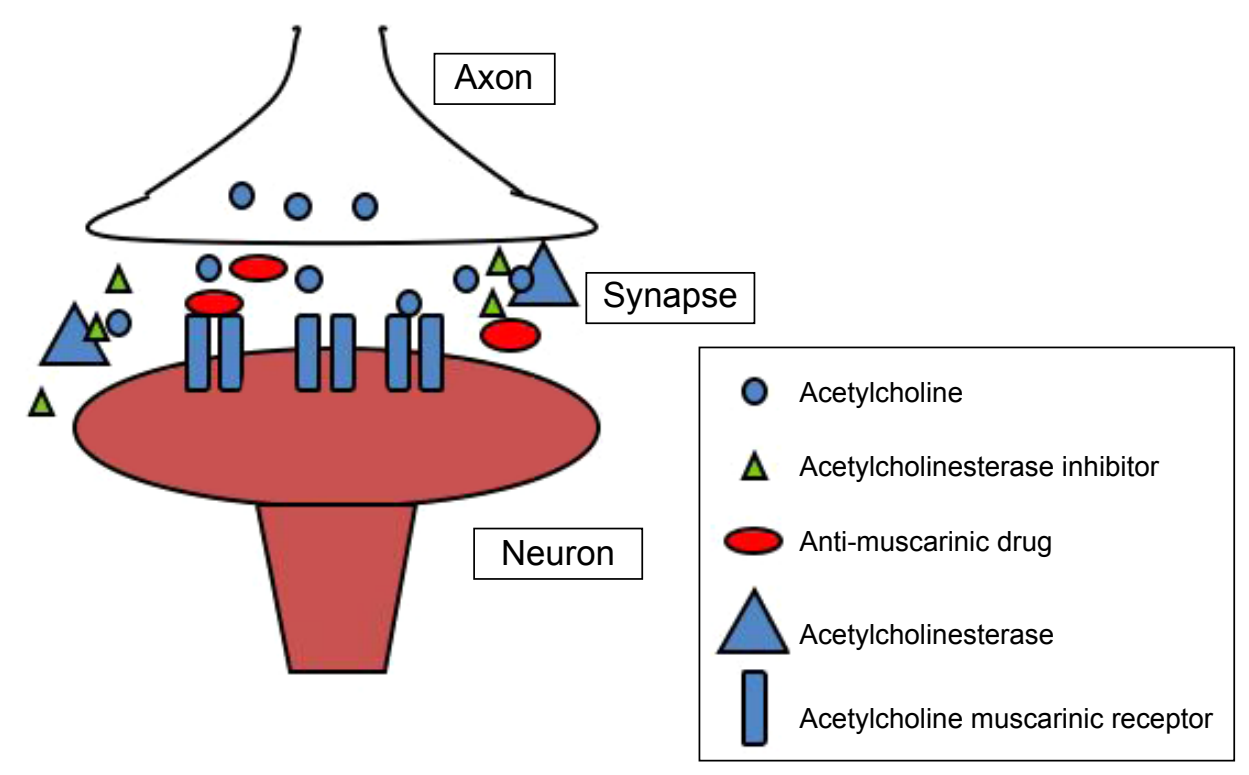

Figure I Pharmacodynamic drug-drug interaction in a cholinergic synapse: acetylcholinesterase inhibitor (AChEl) and anti-muscarinic drug.

Notes: The concomitant administration of AChEls (green triangles) and anticholinergic drugs may result in a pharmacodynamic interaction in the synapse where the beneficial increment of acetyl-choline (blue circle), related to AChE (blue triangles) inhibition, is at least partially reversed by anti-muscarinic drugs (red ellipse) at receptor levels (blue bars).

donepezil over-dosage, ${ }^{74}$ and concomitant use of anticholinergics was not allowed in randomized placebo-controlled trials of AChEIs. ${ }^{75-77}$ As shown by Roe et al the concomitant use of AChEIs and anticholinergic drugs is quite frequent in the Alzheimer population. ${ }^{72}$ Indeed, they found that communitybased elderly individuals with probable dementia are more likely to take anticholinergics than controls. Patients taking donepezil frequently use an anticholinergic medication concomitantly. In particular, they found that $33 \%$ of those taking donepezil also were receiving anticholinergics, compared with $23 \%$ of controls and $26 \%$ of all patients in the study used multiple anticholinergic medications. Similar results were obtained by Carnahan et al in a cross-sectional study to measure the prevalence of anticholinergic drug use in patients receiving cholinesterase inhibitors and to describe change in use of anticholinergics upon inception of AChEI treatment. ${ }^{78}$ They showed that the concurrent use of anticholinergics and AChIs in this cohort reaches 35\%. Also Robinson et al, in an Australian naturalistic study, highlights that co-prescribing of cholinesterase inhibitors and drugs with anticholinergic activity is a common practice and is similar to that seen in other developed countries. ${ }^{79}$ An interesting survey on AChEIs' negative drug-drug interaction was performed by Tavassoli et al. ${ }^{80}$ Analyzing the spontaneous reported ADRs related to AChEIs in France up to 2006, they found that the most frequently reported ADRs, due to drug-drug interaction, in patients treated with AChEIs were associated with bradycardia (54.5\%) and anticholinergic (31.4\%) drugs, in most cases via pharmacodynamic mechanisms. ADRs due to drug-drug interactions were mainly represented by cardiovascular (bradycardia, atrioventricular block [AVB] and arterial hypotension) and neurological (mainly mental confusion) events. ${ }^{80}$

In order to evaluate the impact of the atypical antipsychotics, olanzapine, quetiapine, and risperidone on cognition in patients with $\mathrm{AD}$, Vigen et al carried out a clinical study in 421 AD outpatients with psychosis or agitated/aggressive behavior, randomized to masked, flexible-dose olanzapine, quetiapine, risperidone or placebo. ${ }^{21}$ Patients were followed for 36 weeks and cognitive assessments were obtained at baseline, 12 weeks, 24 weeks, and 36 weeks. Approximately $60 \%$ of those patients were treated concomitantly with AChEIs. The authors found that, in this cohort, atypical antipsychotics were associated with worsening cognitive function compared with placebo. ${ }^{21}$ Anticholinergic related drug effects, as well as those described for antipsychotic agents, can counteract AChEIs' beneficial effect. Considering that anticholinergic drugs can worsen cognitive impairment, they should be administered with caution in elderly patients, especially in AD. The development of an adverse outcome when a demented patient is exposed to anticholinergic drugs, may depend mainly on two factors: total anticholinergic load (ie, use of multiple drugs with anticholinergic activity or use of high doses of these products), and individual pharmacokinetic and pharmacodynamic variability. ${ }^{72}$ Overall, the concurrent use of anticholinergics and AChEIs is quite common 
in a clinical setting but is rarely appropriate considering the pharmacologic antagonism. ${ }^{72}$

\section{Potential ADR at cardiovascular level}

Most of the cardiovascular ADRs to AChEIs might be related to stimulation of the parasympathetic nervous system. ${ }^{81}$ The parasympathetic nervous system can affect heart as well as brain function, and its effect on the heart is more complicated than is generally thought. ${ }^{81}$ Arrhythmia and syncope have been reported with the use of AChEIs. The heart is naturally rich with cholinesterase, and its inhibition may affect cardiac function, especially in elderly patients, many of whom have concomitant cardiovascular disease. The inhibition of cholinesterase by AChEIs retards acetylcholine degradation and potentiates the cardio-inhibitory effect. ${ }^{81}$ Moreover, AChEIs increase arterial blood pressure through central M1 and M2 subtypes of muscarinic receptors ${ }^{80}$ However, the effect of AChEIs is only slight in patients who receive a typical dose. Morganroth et al pooled data from four large placebo-controlled trials in order to assess possible electrocardiogram (ECG) changes associated with rivastigmine. ${ }^{82}$ The authors determined that the incidence of first-degree AVB and bradycardia were higher in the rivastigmine higher dose group when compared with the lower dose and placebo groups, although this difference did not reach statistical significance. A higher incidence of first-degree AVB, increased PR intervals, or decreased heart rates was also found in two trials assessing the safety of donepezil in Alzheimer patients with or without the use of cardiac-related drugs, also in this case, the results were not statistically significant. ${ }^{82,83}$ Although the relationship of bradycardia and syncope with AChEIs remains unclear, there is an increasing number of case reports suggesting a causal relationship. ${ }^{84-86}$ The cardiovascular effects reported for AChEIs and the underlying molecular mechanisms may explain most of the negative drug-drug interactions with other drugs with cardiac activity.

In last few years, there have also been concerns regarding the mortality risk of antipsychotics in people with dementia. The FDA conducted a meta-analysis based on 17 of the short-term atypical antipsychotics in people with $\mathrm{AD}$, highlighting a significant increase in mortality risk for individuals treated with atypical antipsychotics compared to individuals receiving placebo, leading to a "black box" warning regarding mortality risk. ${ }^{87}$ Five meta-analyses on antipsychotic drugs reported a significantly increased risk of cerebrovascular events with atypical antipsychotics compared to placebo. ${ }^{88-93}$ These findings should be interpreted considering that antipsychotic drugs might present a direct effect on the development of cardiovascular events such as QT prolongation, ${ }^{24}$ that could be worsened by drug-drug interactions. In particular, QTc interval prolongation is reported for a number of old and new antipsychotic drugs, such as, haloperidol, levomepromazine, melperone, pimozide, quetiapine, sertindole, thioridazine, or ziprasidone. ${ }^{94-96}$ When an antipsychotic drug affecting QTc prolongation is combined with another QTc-lengthening drug or drugs slowing cardiac frequency (AChEIs), the concomitant use may have additive or even potentiating effects. ${ }^{67}$ Moreover, as suggested by Pariente et al, ${ }^{88}$ we can hypothesize that antipsychotic effects, both on body weight and metabolic syndrome development, seem unlikely in the context of Alzheimer patients. In this setting, if such a pathway is involved, one would expect an over-time progressive increasing risk rather than, as they found, a transient acute risk that decreases thereafter only.

\section{Memantine}

With respect to drug-drug interactions related to memantine it is important to consider that memantine presents a weak dopaminergic agonist with atropinic effects. Memantine should not be administered alongside compounds acting upon the same receptor (NMDA) system (amantadine, ketamine, dextromethorphan) due to the risk of pharmacotoxic psychosis. ${ }^{66}$ There is one published case report on a possible risk for the combination of memantine and phenytoin. ${ }^{67}$

\section{Conclusion}

Alzheimer patients present an increased risk of ADRs and drug-drug interaction ADRs due to several factors such as age, age of disease onset, the presence of multi-pharmacotherapy as well as disease-related CNS alterations that cause sensitization to the effects of psychotropic drugs. Although there are few studies of pharmacokinetic interaction related to Alzheimer patients, considering the potential hepatic effects, it is important to pay attention when prescribing drugs for patients who: ${ }^{97,98} 1$ ) take cytochrome inhibitors of CYP3A4 and CYP2D6; 2) take several cytochrome substrates that compete for the metabolic pathway; 3) present reduced glomerular filtration rate; and 4) are affected by hepatic disease affecting metabolic functions. Another pharmacokinetic interaction that could affect memantine plasma concentration profile in $\mathrm{AD}$ patients is represented by drugs that may alter the urinary $\mathrm{pH}$.

One of the most important pharmacodynamic interactions, based on their opposing mechanisms of action, is represented by the concomitant use of AChEIs and anticholinergic 
drugs that results in pharmacological antagonism. ${ }^{72}$ The anticholinergic effect is a feature of several drugs such as antipsychotics, antidepressants, antihistamines, bronchodilators, and drugs for urinary incontinence that are frequently prescribed to Alzheimer patients, especially to those with behavioral and psychotic symptoms. Finally, in this setting, we have to consider the cardiovascular adverse reaction related to the drugs, keeping in mind the possible alteration in the rhythm and the QT.

\section{Disclosure}

The authors have no conflicts of interest to disclose.

\section{References}

1. Buxton IL, Benet LZ. Pharmacokinetics: The Dynamics of Drug Absorption, Distribution, Metabolism, and Elimination. In: Brunton LL, Chabner BA, Knollmann BC, editors. Goodman \& Gilman's The Pharmacological Basis of Therapeutic. 12th ed. New York: McGrawHill; 2011.

2. Mallet L, Spinewine A, Huang A. The challenge of managing drug interactions in elderly people. Lancet. 2007;370(9582):185-191.

3. Hanlon JT, Lindblad CI, Hajjar ER, McCarthy TC. Update on drug-related problems in the elderly. Am J Geriatr Pharmacother. 2003;1(1):38-43.

4. Gurwitz JH, Field TS, Harrold LR, et al. Incidence and preventability of adverse events among older persons in the ambulatory setting. JAMA. 2003;289(9):1107-1116.

5. Tangiisuran B, Wright J, Van der Cammen T, Rajkumar C. Adverse drug reactions in elderly: challenges in identification and improving preventative strategies. Age Ageing. 2009;38(4):358-359.

6. Seeley WW, Miller BL. Dementia. In: Longo DL, Fauci AS, Kasper DL, Hauser SH, Jameson JL, Loscalzo J, editors. Harrison's Principles of Internal Medicine. 18th ed. New York: McGraw-Hill; 2012.

7. Lyketsos CG, Steinberg M, Tschanz JT, et al. Mental and behavioral disturbances in dementia: indings from the Cache County Study on Memory in Aging. Am J Psychiatry. 2000;157(5):708-714.

8. Ropacki SA, Jeste DV. Epidemiology of and risk factors for psy-chosis of Alzheimer's disease: a review of 55 studies published from 1990 to 2003. Am J Psychiatry. 2005;162(11):2022-2030.

9. López OL, Zivkovic G, Smith G, Becker JT, Meltzer CC, DeKosky ST. Psychiatric symptoms associated with cortical-subcortical dysfunction in Alzheimer's disease. J Neuropsychiatry Clin Neurosci. 2001;13(1):56-60.

10. Andersen F, Viitanen M, Halvorsen DS, Straume B, Engstad TA. Co-morbidity and drug treatment in Alzheimer's disease. A cross sectional study of participants in the dementia study in northern Norway. BMC Geriatr. 2011;11:58.

11. Heun R, Schoepf D, Potluri R, Natalwala A. Alzheimer's disease and co-morbidity: increased prevalence and possible risk factors of excess mortality in a naturalistic 7-year follow-up. Eur Psychiatry. 2013;28(1): 40-48.

12. Small GW, Rabins PV, Barry PP, et al. Diagnosis and treatment of Alzheimer's disease and related disorders. Consensus statement of the American Association for Geriatric Psychiatry, the Alzheimer's Association, and the American Geriatrics Society. JAMA. 1997;278(16): 1363-1371.

13. Brauner DJ, Muir JC, Sachs GA. Treating nondementia illnesses in patients with dementia. JAMA. 2000;283(24):3230-3235.

14. O'Brien JT, Burns A; BAP Dementia Consensus Group. Clinical practice with anti-dementia drugs: a revised (second) consensus statement from the British Association for Psychopharmacology. J Psychopharmacol. 2011;25(8):997-1019.
15. Giron MS, Forsell Y, Bernsten C, Thorslund M, Winblad B, Fastbom J. Psychotropic drug use in elderly people with and without dementia. Int J Geriatr Psychiatry. 2001;16(9):900-906.

16. Olin JT, Katz IR, Meyers BS, Schneider LS, Lebowitz BD. Provisional diagnostic criteria for depression of Alzheimer disease: rationale and background. Am J Geriatr Psychiatry. 2002;10(2):129-141.

17. Sink KM, Holden KF, Yaffe K. Pharmacological treatment of neuropsychiatric symptoms of dementia: a review of the evidence. JAMA. 2005;293(5):596-608.

18. Gauthier S, Cummings J, Ballard C, et al. Management of behavioral problems in Alzheimer's disease. Int Psychogeriatr. 2010;22(3):346-372.

19. Schneider LS, Dagerman K, Insel PS. Efficacy and adverse effects of atypical antipsychotics for dementia: meta-analysis of randomized, placebocontrolled trials. Am J Geriatr Psychiatry. 2006;14(3):191-210.

20. Gardette V, Lapeyre-Mestre M, Coley N, et al. Antipsychotic use and mortality risk in community-dwelling Alzheimer's disease patients: evidence for a role of dementia severity. Curr Alzheimer Res. 2012; 9(9):1106-1116.

21. Vigen CL, Mack WJ, Keefe RS, et al. Cognitive effects of atypical antipsychotic medications in patients with Alzheimer's disease: outcomes from CATIE-AD. Am J Psychiatry. 2011;168(8):831-839.

22. Lee PE, Gill SS, Freedman M, Bronskill SE, Hillmer MP, Rochon PA. Atypical antipsychotic drugs in the treatment of behavioural and psychological symptoms of dementia: systematic review. BMJ. 2004;329(7457):75.

23. Pariente A, Sanctussy DJ, Miremont-Salame G, et al. Factors associated with serious adverse reactions to cholinesterase inhibitors: a study of spontaneous reporting. CNS Drugs. 2010;24(1):55-63.

24. Perera G, Khondoker M, Broadbent M, Breen G, Stewart R. Factors associated with response to acetylcholinesterase inhibition in dementia: a cohort study from a secondary mental health care case register in London. PLoS One. 2014;9(11):e109484.

25. Wang PS, Schneeweiss S, Avorn J, et al. Risk of death in elderly users of conventional vs atypical antipsychotic medications. $N$ Engl J Med. 2005;353(22):2335-2341.

26. Gill SS, Rochon PA, Herrmann N, et al. Atypical antipsychotic drugs and risk of ischaemic stroke: population based retrospective cohort study. BMJ. 2005;330(7489):e445.

27. Douglas IJ, Smeeth L. Exposure to antipsychotics and risk of stroke: self-controlled case series study. BMJ. 2008;337:a1227.

28. Maher AR, Maglione M, Bagley S, et al. Efficacy and comparative effectiveness of atypical antipsychotic medications for offlabel uses in adults: a systematic review and meta-analysis. JAMA. 2011;306(12):1359-1369

29. Liu ME, Tsai SJ, Chang WC, et al. Population-based 5-year follow-up study in Taiwan of dementia and risk of stroke. PLoS One. 2013;8(4):e61771.

30. Trifirò G, Verhamme KM, Ziere G, Caputi AP, Ch Stricker BH, Sturkenboom MC. All-cause mortality associated with atypical and typical antipsychotics in demented outpatients. Pharmacoepidemiol Drug Saf. 2007;16(5):538-544.

31. Young A. Ageing and physiological functions. Philos Trans R Soc Lond B Biol Sci. 1997;352(1363):1837-1843.

32. Muhlberg W, Platt D. Age-dependent changes of the kidneys: Pharmacological implications. Gerontology. 1999;45(5):243-253.

33. Fulop T Jr, Worum I, Csongor J, Fo' ris G, Leovey A. Body composition in elderly people: I. Determination of body composition by multiisotope method and the elimination kinetics of these isotopes in healthy elderly subjects. Gerontology. 1985;31(1):6-14.

34. McLean AJ, Le Couteur DG. Aging biology and geriatric clinical pharmacology. Pharmacol Rev. 2004;56(2):163-184.

35. Ginsberg G, Hattis D, Russ A, Sonawane B. Pharmacokinetic and pharmacodynamic factors that can affect sensitivity to neurotoxic sequelae in elderly individuals. Environ Health Perspect. 2005;113(9):1243-1249.

36. Bentue-Ferrer D, Tribut O, Polard E, Allain H. Clinically significant drug interactions with cholinesterase inhibitors: a guide for neurologists. CNS Drugs. 2003;17(13):947-963. 
37. Zoli M, Magalotti D, Bianchi G, et al. Total and functional hepatic blood flow decrease in parallel with ageing. Age Ageing. 1999;28(1):29-33.

38. Wynne HA, Cope LH, Mutch E, Rawlins MD, Woodhouse KW, James OF. The effect of age upon liver volume and apparent liver blood flow in healthy man. Hepatology. 1989;9(2):297-301.

39. Fliser D, Zeier M, Nowack R, Ritz E. Renal functional reserve in healthy elderly subjects. J Am Soc Nephrol. 1993;3(7):1371-1377.

40. Trifirò G, Spina E. Age-related changes in pharmacodynamics: focus on drugs acting on central nervous and cardiovascular systems. Curr Drug Metab. 2011;12(7):611-620.

41. Mangoni AA, Jackson SH. Age-related changes in pharmacokinetics and pharmacodynamics: basic principles and practical applications. Br J Clin Pharmacol. 2004;57(1):6-14.

42. Kruse WH. Problems and pitfalls in the use of benzodiazepines in the elderly. Drug Saf. 1990;5(5):328-334.

43. Swift CG, Ewen JM, Clarke P, Stevenson IH. Responsiveness to oral diazepam in the elderly: relationship to total and free plasma concentrations. Br J Clin Pharmacol. 1985;20(2):111-118.

44. Reidenberg MM, Levy M, Warner H, et al. Relationship between diazepam dose, plasma level, age, and central nervous system depression. Clin Pharmacol Ther. 1978;23(4):371-374.

45. Castleden CM, George CF, Marcer D, Hallett C. Increased sensitivity to nitrazepam in old age. Br Med J. 1977;1(6052):10-12.

46. Greenblatt DJ, Divoll M, Harmatz JS, MacLaughlin DS, Shader RI. Kinetics and clinical effects of flurazepam in young and elderly noninsomniacs. Clin Pharmacol Ther. 1981;30(4):475-486.

47. Cummings JL. Alzheimer's disease. N Engl J Med. 2004;351(1): 56-67.

48. Archer HA, Edison P, Brooks DJ, et al. Amyloid load and cerebral atrophy in Alzheimer's disease: an 11C-PIB positron emission tomography study. Ann Neurol. 2006;60(1):145-147.

49. West MJ, Kawas CH, Stewart WF, Rudow GL, Troncoso JC. Hippocampal neurons in pre-clinical Alzheimer's disease. Neurobiol Aging 2004;25(9):1205-1212.

50. Morrison JH, Hof PR. Life and death of neurons in the aging brain. Science. 1997;278(5337):412-419.

51. Morrison JH, Hof PR. Selective vulnerability of corticocortical and hippocampal circuits in aging and Alzheimer's disease. Prog Brain Res. 2002;136:467-486.

52. Hof PR, Bussière T, Gold G, et al. Stereologic evidence for persistence of viable neurons in layer II of the entorhinal cortex and the CA1 field in Alzheimer disease. J Neuropathol Exp Neurol. 2003;62(1):55-67.

53. Cummings JL, Back C. The cholinergic hypothesis of neuropsychiatric symptoms in Alzheimer's disease. Am J Geriatr Psychiatry. 1998; 6(2 Suppl 1):64-78.

54. Mufson EJ, Counts SE, Perez SE, Ginsberg SD. Cholinergic system during the progression of Alzheimer's disease: therapeutic implications. Expert Rev Neurother. 2008;8(11):1703-1718.

55. Raina P, Santaguida P, Ismaila A, et al. Effectiveness of cholinesterase inhibitors and memantine for treating dementia: evidence review for a clinical practice guideline. Ann Intern Med. 2008;148(5):379-397.

56. Howard R, McShane R, Lindesay J, et al. Donepezil and memantine for moderate-to-severe Alzheimer's disease. N Engl J Med. 2012;366(10): 893-903.

57. Spina E, Scordo MG, D'Arrigo C. Metabolic drug interactions with new psychotropic agents. Fundam Clin Pharmacol. 2003;17(5): $517-538$

58. Sweeney BP, Bromilow J. Liver enzyme induction and inhibition: implications for anaesthesia. Anaesthesia. 2006;61(2):159-177.

59. Tiseo PJ, Perdomo CA, Friedhoff LT. Concurrent administration of donepezil $\mathrm{HCl}$ and ketoconazole: assessment of pharmacokinetic changes following single and multiple doses. Br J Clin Pharmacol. 1998; 46 Suppl 1:30-34.

60. Nagy CF, Kumar D, Perdomo CA, Wason S, Cullen EI, Pratt RD. Concurrent administration of donepezil $\mathrm{HCl}$ and sertraline $\mathrm{HCl}$ in healthy volunteers: assessment of pharmacokinetic changes and safety following single and multiple oral doses. Br J Clin Pharmacol. 2004;58 Suppl 1:25-33.
61. Huang F, Fu Y. A review of clinical pharmacokinetics and pharmacodynamics of galantamine, a reversible acetylcholinesterase inhibitor for the treatment of Alzheimer's disease, in healthy subjects and patients. Curr Clin Pharmacol. 2010;5(2):115-124.

62. Piotrovsky V, Van Peer A, Van Osselaer N, Armstrong M, Aerssens J. Galantamine population pharmacokinetics in patients with Alzheimer's disease: modeling and simulations. J Clin Pharmacol. 2003;43(5): 514-523.

63. Grossberg GT, Stahelin HB, Messina JC, Anand R, Veach J. Lack of adverse pharmacodynamic drug interactions with rivastigmine and twenty-two classes of medications. Int $J$ Geriatr Psychiatry. 2000;15(3):242-247.

64. Wesemann W, Sonntag K-H, Maj J. On the pharmacodynamics and pharmacokinetics of memantine. Drug Res. 1983;33(8):1122-1134.

65. Roy SD, Hawes EM, Midha KK. Influence of urinary $\mathrm{pH}$ on the disposition of methoxyphenamine and three metabolites in humans. J Pharm Sci. 1987;76(6):427-432.

66. Freudenthaler S, Meineke I, Schreeb KH, Boakye E, Gundert-Remy U, Gleiter $\mathrm{CH}$. Influence of urine $\mathrm{pH}$ and urinary flow on the renal excretion of memantine. Br J Clin Pharmacol. 1998;46(6):541-546.

67. European Medicine Agency. Ebixa Tablets SPC, Summary of Product Characteristics. European Medicine Agency (EMA). Available from: http://www.ema.europa.eu/docs/en_GB/document_library/EPAR_-_ Product_Information/human/000463/WC500058763.pdf. Accessed August 15, 2015.

68. Hiemke C, Pfuhlmann B. Interactions and monitoring of antipsychotic drugs. Handb Exp Pharmacol. 2012;(212):241-265.

69. Castberg I, Skogvoll E, Spigset O. Quetiapine and drug interactions: evidence from a routine therapeutic drug monitoring service. J Clin Psychiatry. 2007;68(10):1540-1545.

70. Nickl-Jockschat T, Paulzen M, Schneider F, Grozinger M. Drug interaction can lead to undetectable serum concentrations of quetiapine in the presence of carbamazepine. Clin Neuropharmacol. 2009;32(1):55.

71. Whitehouse PJ, Price DL, Struble RG, Clark AW, Coyle JT, Delon MR. Alzheimer's disease and senile dementia: loss of neurons in the basal forebrain. Science. 1982;215(4537):1237-1239.

72. Roe CM, Anderson MJ, Spivack B. Use of anticholinergic medications by older adults with dementia. J Am Geriatr Soc. 2002;50(5):836-842.

73. American Geriatrics Society 2012 Beers Criteria Update Expert Panel. American Geriatrics Society updated Beers Criteria for potentially inappropriate medication use in older adults. J Am Geriatr Soc. 2012; 60(4):616-631.

74. Shepherd G, Klein-Schwartz W, Edwards R. Donepezil overdose: A tenfold dosing error. Ann Pharmacother. 1999;33(7):812-815.

75. Rösler M, Anand R, Cicin-Sain A, et al. Efficacy and safety of rivastigmine in patients with Alzheimer's disease: International randomised controlled trial. BMJ. 1999;318(7184):633-638.

76. Corey-Bloom J, Anand R, Veach J. A randomized trial evaluating the efficacy and safety of ENA 713 (rivastigmine tartrate), a new acetylcholinesterase inhibitor, in patients with mild to moderately severe Alzheimer's disease. Int J Ger Psychopharmacol. 1998;1:55-65.

77. Tariot PN, Solomon PR, Morris JC, et al. A 5-month, randomized, placebocontrolled trial of galantamine in AD. Neurology. 2000;54(12):2269-2276.

78. Carnahan RM, Lund BC, Perry PJ, Chriscilles EA. The concurrent use of anticholinergics and cholinesterase inhibitors: rare event or common practice? J Am Geriatr Soc. 2004;52(12):2082-2087.

79. Robinson M, Rowett D, Leverton A, Mabbott V. Changes in utilisation of anticholinergic drugs after initiation of cholinesterase inhibitors. Pharmacoepidemiol Drug Saf. 2009;18(8):659-664.

80. Tavassoli N, Sommet A, Lapeyre-Mestre M, Bagheri H, Montrastruc JL. Drug interactions with cholinesterase inhibitors: an analysis of the French pharmacovigilance database and a comparison of two national drug formularies (Vidal, British National Formulary). Drug Saf. 2007;30(11):1063-1071.

81. Masuda Y. Cardiac effect of cholinesterase inhibitors used in Alzheimer's disease - from basic research to bedside. Curr Alzheimer Res. 2004;1(4):315-321. 
82. Morganroth J, Graham S, Hartman R, Anand R. Electrocardiographic effects of rivastigmine. J Clin Pharmacol. 2002;42(5):558-568.

83. Bordier P, Garrigue S, Barold SS, Bressolles N, Lanusse S, Clémenty J. Significance of syncope in patients with Alzheimer's disease treated with cholinesterase inhibitors. Europace. 2003;5(5):429-431.

84. Bordier P, Garrigue S, Lanusse S, et al. Cardiovascular effects and risk of syncope related to donepezil in patients with Alzheimer's disease. CNS Drugs. 2006;20(5):411-417.

85. Kayrak M, Yazici M, Ayhan SS, Koc F, Ulgen MS. Complete atrioventricular block associated with rivastigmine therapy. Am J Health Syst Pharm. 2008;65(11):1051-1053.

86. Paulison B, Léos CL. Potential cardiotoxic reaction involving rivastigmine and beta-blockers: a case report and review of the literature. Cardiovasc Toxicol. 2010;10(4):306-310.

87. US Food and Drug Administration. Deaths with Antipsychotics in Elderly Patients with Behavioral Disturbances. US Food and Drug Administration; 2005. Available from: http://www.cchrint.org/pdfs/ US_Food_and_Drug_Administration_Warnings_on_Antipsychotic_ Drugs.pdf. Accessed August 15, 2015.

88. Pariente A, Fourrier-Réglat A, Ducruet T, et al. Antipsychotic use and myocardial infarction in older patients with treated dementia. Arch Intern Med. 2012;172(8):648-653.

89. Pratt N, Roughead EE, Salter A, Ryan P. Choice of observational study design impacts on measurement of antipsychotic risks in the elderly: a systematic review. BMC Med Res Methodol. 2012;12:72.

90. Ballard C, Waite J. The effectiveness of atypical antipsychotics for the treatment of aggression and psychosis in Alzheimer's disease. Cochrane Database Syst Rev. 2006;(1):CD003476.
91. De Deyn PP, Katz IR, Brodaty H, Lyons B, Greenspan A, Burns A. Management of agitation, aggression, and psychosis associated with dementia: a pooled analysis including three randomized, placebocontrolled double-blind trials in nursing home residents treated with risperidone. Clin Neurol Neurosurg. 2005;107(6):497-508.

92. Schneider LS, Tariot PN, Dagerman KS, et al. Effectiveness of atypical antipsychotic drugs in patients with Alzheimer's disease. NEngl J Med. 2006;355(15):1525-1538.

93. Herrmann N, Lanctot KL. Do atypical antipsychotics cause stroke? CNS Drugs. 2005;19(2):91-103.

94. Van Noord C, Eijgelsheim M, Stricker BH. Drug- and non-drugassociated QT interval prolongation. Br J Clin Pharmacol. 2010;70(1): $16-23$.

95. Wenzel-Seifert K, Wittmann M, Haen E. QTc prolongation by psychotropic drugs and the risk of Torsade de Pointes. Dtsch Arztebl In. 2011;108(41):687-693.

96. Bressler R. Grapefruit juice and drug interactions. Exploring mechanisms of this interaction and potential toxicity for certain drugs. Geriatrics. 2006;61(11):12-18.

97. Ingelman-Sundberg M. Genetic polymorphisms of cytochrome P450 2D6 (CYP2D6): clinical consequences, evolutionary aspects and functional diversity. Pharmacogenomics J. 2005;5(1):6-13.

98. Zhou SF, Xue CC, Yu XQ, Li C, Wang G. Clinically important drug interactions potentially involving mechanism-based inhibition of cytochrome P450 3A4 and the role of therapeutic drug monitoring. Ther Drug Monit. 2007;29(6):687-710.
Clinical Interventions in Aging

\section{Publish your work in this journal}

Clinical Interventions in Aging is an international, peer-reviewed journal focusing on evidence-based reports on the value or lack thereof of treatments intended to prevent or delay the onset of maladaptive correlates of aging in human beings. This journal is indexed on PubMed Central, MedLine,

\section{Dovepress}

CAS, Scopus and the Elsevier Bibliographic databases. The manuscript management system is completely online and includes a very quick and fair peer-review system, which is all easy to use. Visit http://www.dovepress. com/testimonials.php to read real quotes from published authors. 